\title{
COMMENTARY
}

\section{Is natural history really dead? Toward the rebirth of natural history}

\author{
¿Está realmente muerta la historia natural? Hacia el renacimiento de la Historia Natural
}

MARY F. WILLSON \& JUAN J. ARMESTO*

\author{
Fundación Senda Darwin and Center for Advanced Studies in Ecology and Biodiversity, \\ Pontificia Universidad Católica de Chile, Casilla 114-D, Santiago, Chile; \\ Instituto de Ecología \& Biodiversidad, Universidad de Chile; \\ * e-mail for correspondence: jarmesto@bio.puc.cl
}

\begin{abstract}
In recent years natural history has been derided by some scientists as an old-fashion endeavor that does not follow the model of "hard" science and therefore should be considered "dead" and replaced by modern ecology, evolutionary biology, and conservation biology. We contend that natural history has much to offer to contemporary scientists and that it has a primary role in the creative process of generating novel hypotheses and designing significant field experiments and observations.
\end{abstract}

Key words: ecology, naturalists, biologists, basic science.

\section{RESUMEN}

En años recientes, la historia natural ha sido desacreditada por científicos que la consideran un modelo obsoleto de ciencia y que, en consecuencia, se trataría de una disciplina "muerta" que ha sido reemplazada por la ecología moderna, la biología evolutiva y la biología de la conservación. Argumentamos aquí que la historia natural tiene mucho que ofrecer a los científicos contemporáneos y que juega un rol principal en el proceso de creación de hipótesis y en el diseño acertado de observaciones y experimentos de campo.

Palabras clave: biólogos, ecología, ciencia básica, naturalistas.

"Natural historians have too often been apologetic...in supporting a plurality of legitimately scientific modes".

S.J. Gould (2002), p. 1333.

In recent years, natural history has been derided by numerous scientists (both in and out of biology) as old-fashioned and nonscientific, and therefore it is an endeavor that should be dead, if it is not so already. A parallel argument disdains natural history as an approach that has been superseded by modern disciplines incorporating physiological, molecular or modeling approaches (Jaksic 1999). At the beginning of the $20^{\text {th }}$ century, the model of science represented by natural history began to be replaced by the emerging biological disciplines of physiology, morphology, and ecology, characterized by greater specialization, methodological rigor, and stronger theoretical foundations (McIntosh 1985). This shift led to a philosophical division between natural history and much of the rest of biology that, from the beginning, has sometimes impaired intellectual progress. For example, Dobzhansky (1980) recalled that his early effort to fuse experimental genetics with systematics and natural history was held back by a predominantly reductionist view of biology. Gould (2002) attributed the early breakup between natural history and the rest of biology to the misconception that science, in its "highest" form, should explain natural phenomena only by general laws, with the consequent disregard for historical explanations. The profound division between so-called "big science" and natural history seems to have 
deepened as a result of the uncritical embracing of the prevailing model of hypothetico-deductive science by ecologists in the 1970's (Armesto 1985). Like Gould (2002), we contend that this narrow view of ecological science should give way to a broader conceptualization, admitting a pluralism of relevant and appropriate styles of inquiry. Similar arguments have been put forward by other ecologists (e.g., Pickett et al. 1994) but have not been broadly accepted or formally discussed in academic circles.

However, there have been a few instances when respected biologists defied the general $20^{\text {th }}$ century trend toward denigration of natural history. For example, as late as the 1950s, the eminent behavioral ecologist Niko Tinbergen was not ashamed to write about himself and his students as 'Curious Naturalists', describing both their observations and experimental, hypothesis-testing work. More recently, the biologist E.O. Wilson was so conscious of the scientific relevance of natural history as to entitle his autobiography "Naturalist". Various contemporary scientists have decried the decline of interest in taxonomy and systematics, an important ally of natural history, at a time when so much of the world's biodiversity is still unknown but vulnerable to anthropogenic destruction (Wilson 1988). Still other biologists have lamented the demise of natural history courses in college curricula (Noss 1996, Schmidly 2005). Academic institutions, except for some museums, no longer use this denomination for their science departments, either by choice or necessity. The prevailing view seems to be that natural history is hopelessly old-fashioned, unscientific, sloppy, and useless. Statements such as this can be especially misguiding to young naturalists and graduate students. Clearly, the field known as natural history is in some kind of disrepair and disrepute, and opinions differ widely as to its continued value.

In this essay, we discuss the place of natural history in relation to biological science and conservation biology. We argue that natural history is probably not really dead, certainly should not be treated as dead, and indeed warrants enthusiastic encouragement from scientists and laypersons alike.

What is natural history? One definition says that it is the study of the natural world and natural phenomena (Lincoln et al. 1983). Other authors have used the term to refer to the general knowledge about the biota of a region (Janzen 1983). From its inception as a discipline, natural history was at the roots of modern evolutionary biology and ecology, and Charles Darwin is recognized as one of its champions (Gould 2002). In line with this historical view, natural history is one of the major disciplines, together with experimental and population genetics, that gave rise to the modern evolutionary synthesis (Mayr 1980). Natural history is, in this perspective, fundamental to all biology whose main goal is to understand biological diversity.

To show the linkages of the discipline of natural history to the practice of science, we propose that there are several levels of natural history. The most elementary level might be a simple, but interesting, observation, such as "I saw a bee do this strange thing..." The next level of natural history might be a simple list of flowers visited by a certain kind of bee, or of avian visitors to a fruiting tree. This might be followed by the identification of some measurable descriptor, such as the time spent per flower or the number of fruits eaten per visit, or a comparative analysis of the floral hosts of two kinds of bee or the frugivores active in two different habitats. These kinds of simple observations characterize "natural history' in a very limited sense, but good natural history does not stop here. Such observations may lead to the discovery of intriguing patterns (e.g., more bees visit blue flowers than white flowers), and interesting questions (e.g., what are the selection pressures on flower color? How is the color of the flowers related to bee visitation patterns?) for which some explanation or answer is desirable. At this point, following the explicit account of patterns and questions, standard scientific methods of hypothesis testing become possible and relevant. But one cannot arrive at this point without the preceding elementary observations.

Some scientists say that, while natural history consists of the discovery of patterns in nature, "science" consists of the examination of mechanisms that produce the observed patterns. None of the elementary levels of natural history described in the above paragraph constitutes "science" in the narrow sense of testing hypotheses or building deductive theory about mechanisms to explain patterns. But they do 
provide the necessary building blocks that stimulate the process of scientific inquiry, mamely the framing of focused and interesting questions and construction of simple hypotheses (see also Feinsinger 2001). In addition to providing the observational building blocks of ecological inquiry, natural history knowledge of the focal organisms and ecosystems (e.g., Janzen 1983 ) provides information necessary for designing effective experiments and planning critical observations regarding the questions at hand. For example, to understand the distribution and population dynamics of the narrowly endemic Churrín de la Mocha (Eugralla paradoxa) in Chilean rain forests, it is essential to know the multiyear flowering and fruiting cycle of the native bamboo (Chusquea quila), which provides favored habitat for this bird species. The relevant temporal and spatial contexts are also part of the essential natural history framework (Feinsinger 2001). Knowledge of changes in seasonal habitat use of pollinators, for example, could be essential to designing well-focused experiments on factors that limit seed set or to understanding networks of mutualistic interactions.

Some practitioners of science narrowly define "science" only as the testing of hypotheses - apparently considering the process of construction of testable hypotheses to be outside the scientific process (!!). In this view, the hypotheses might just as well spring full-blown from the head of Zeus as derive from foregoing observations of natural phenomena. In contrast to the narrow vision for the domain of science held by those who would include only the testing of hypotheses, Ayala (1994) clearly saw the formulation of hypotheses as an integral part of science, requiring innovation, imagination, and use of previously acquired information, to be followed by validation or confirmation by hypothesis testing. Other scientists (e.g., Bartholomew 1986) have argued for the value of natural history's synthetic, integrative power, in opposition to the exclusionist, narrow viewpoint that overemphasizes strict reductionism in biology. We suggest, in addition, that a good and focused question, based on careful preliminary observations, is particularly useful and essential to initiate the "inquiry cycle" (Feinsinger 2001), especially when there is too little existing information to frame a useful or interesting hypothesis. Exploring an interesting question would usually entail the testing of several subsequent hypotheses that cover various mechanisms that may have produced the observed pattern or various possible consequences of the observed pattern or process (e.g., for seed dispersal, escape from enemies near the maternal parent or arrival at sites with lower density of relatives, etc.). But the initial important step is conceiving an appealing question - e.g., that dispersal distance may have consequences, both in terms of the evolution of dispersal and of population structure.

There are even times when a good appealing question is worth far more than a poorly conceived, deductive, hypothesis, however well the latter seems to fit the expectations of the narrow definition of science. For example, we have, in our academic lives, run across hypotheses of the sort "seed germination is affected by temperature" (null hypothesis: no effect). This is often the case when students are forced to frame their studies within the narrow definition of science only as hypothesis testing. This statement is basically worthless, scientifically, because at some temperature (e.g., lethal levels) germination must be affected, and any outcome of a temperature experiment could render the so-called hypothesis acceptable, although it would still be uninformative. Much more informative, initially, would be a question that asks: what is the response of seed germination to temperature, followed by a description of germination rates on a temperature gradient. From the ensuing data could be built a model of responses to temperature as a useful tool for generating meaningful hypotheses and predictions.

Even acceptably good hypotheses by current hypothetico-deductive standards, in the absence of synthesis and induction, lead ineluctably to an undesirable situation in which one is learning more and more about less and less. The ultra-reductionist approach in biology may be legitimate science, but it is not the only kind of valid biological science, and its value is necessarily limited without the context and connections provided by natural history.

A broader definition of "science" must include both the generation and testing of hypotheses, and, more broadly still, should include the processes of synthesis and induction 
that produce unifying concepts and theoretical constructs (Pickett et al. 1994, Feinsinger 2001). If one accepts these broader views of what science is, then it becomes difficult to segregate the natural-history building blocks that lead to the generation of interesting questions and hypotheses into a category of nonscience. Development of a good research hypothesis requires a deep understanding of the existing relevant knowledge base derived from natural history (Ayala 1994, Grogan 2005). Very commonly, it is simple natural history observations, planned or unplanned, that tweak the imagination into challenging existing dogma, asking novel questions, and seeing natural phenomena from a different perspective. If natural history is killed, either by intent or neglect, then one is assuming that we already have all the basic observations needed to understand the natural world; this assumption strikes us as supremely arrogant, not to mention stultifying. Relationships between organisms and their environments are so varied, and so contingent on historical context, that we are a long way from knowing even all the patterns of nature, much less knowing all the mechanisms and consequences. In addition, natural history observations are often used to test inductive or deductive hypotheses, either in conjunction with experiments or alone, when experiments are infeasible. Furthermore, good natural history would also be informed by a feedback process from other branches of science, using concepts and perspectives to focus the questions asked by the observer (Green 2005). So it seems that natural history is an integral part of the process of scientific inquiry in ecology and evolution.

It can hardly be true that natural history has transmogrified into conservation biology (Jaksic 1999), a field that uses information from many other sources, including theoretical biology, economics, genetics, biogeography, and epidemiology, none of which is equivalent to natural history. Natural history does provide concrete, specific information needed for conservation of particular species (e.g., habitat use, such as for E. paradoxa) or ecosystems. Furthermore, good natural history, born from curiosity and fascination with nature, does contribute ethical values to the conservation effort. Conservation attitudes often derive from heartfelt appreciation of the natural systems of interest and the consequences of our actions, and those values originate from very elementary knowledge of natural history, such as lists of butterflies seen in our home or school garden or pleasure in the song of a bird. Such ethical values should be encouraged by ecology education programs, especially for those whose minds are still young as well as for citizens visiting wildlife reserves (Armesto et al. 1996, Feinsinger et al. 1997). Natural history is the aspect of biological science most accessible to the layperson, and therefore possibly the most likely to make conservation relevant to them. Similarly, the teaching of natural history generally provides the inspiration and challenge to students that stimulates the coming generation of biologists and conservationists (Page 2005). A broad view of science, including natural history as a source of novel questions and ethical values, contrasts dramatically with the common use of modern science and derived technology merely to increase human domination and appropriation of earth's ecosystems for human profit (Vitousek et al. 1997, Noble \& Dirzo 1997). Intelligent use of natural history information by managers could foster the use of forest ecosystems with less destructiveness than is presently occurring.

In short, we submit that, in addition to being recognized as the historical roots of modern biology and evolution, natural history currently contributes essential building blocks to the scientific process, generates challenges that lead to reorganization of conventional paradigms, and offers both essential information and ethical values to conservation and management efforts. Therefore, we believe that natural history is not really dead and certainly should not be further damaged or killed outright, as it is a necessary and humanizing component of $21^{\text {st }}$ century science (Schmidly 2005). We urge that good natural history be restored to a position of respectability or even moderate honor in the scientific community. This a contribution to the research program of Senda Darwin Biological Station.

\section{ACKNOWLEDGEMENTS}

We thank the field crews at Senda Darwin Biological Station (2001) for helpful discussion, and appreciate reviews by $\mathrm{J}$. Cuevas, P. Feinsinger, F. Jaksic, J. Kenagy, 
S.T.A. Pickett, R. Rozzi, and two anonymous reviewers. This collaboration was supported by FONDAP-FONDECYT 1501-0001 and Millennium Nucleus P99-103 FICM.

\section{LITERATURE CITED}

ARMESTO JJ (1985) Prueba de hipótesis en ecología: una crítica al método científico formal. Revista Chilena de Historia Natural 58: 107-108.

ARMESTO JJ, R ROZZI \& MF WILLSON (1996) Bridging scientific knowledge, education, and application in temperate ecosystems of southern South America. Bulletin of the Ecological Society of America 77: 120-122

AYALA FJ (1994) On the scientific method, its practice and pitfalls. History and Philosophy of the Life Sciences 16: 205-240.

BARTHOLOMEW GA (1986) The role of natural history in contemporary biology. BioScience $36: 324-329$

FEINSINGER P (2001) Designing field studies for biodiversity conservation. Island Press, Washington, District of Columbia, USA. 212 pp.

FEINSINGER P, L MARGUTTI \& RD OVIEDO (1997) School yards and nature trails: ecology education outside the university. Trends in Ecology \& Evolution 12: 115-120

GOULD SJ (2002) The structure of evolutionary theory. The Belknam Press of Harvard University Press, Cambridge, Massachusetts, USA. 1,433 pp.

GREEN HW (2005) Organisms in nature as a central focus for biology. Trends in Ecology \& Evolution 20: 23-27.

Associate Editor: G.J. Kenagy

Received March 11, 2005; accepted April 17, 2006
GROGAN P (2005) The use of hypotheses in ecology. Bulletin of the British Ecological Society 36: 43-47.

JAKSIC FM (1999) ¿Qué fue de la historia natural? Revista Chilena de Historia Natural 72: 5-6.

JANZEN DH (ed) (1983) Costa Rican natural history. First edition. University of Chicago Press, Chicago, Illinois, USA. 816 pp.

LINCOLN LJ, GA BOXSHALL \& PF CLARK (1983) A dictionary of ecology, evolution, and systematics. Second edition. Cambridge University Press, Cambridge, United Kingdom. 298 pp.

MAYR E (1980) How I became a Darwinian. In: Mayr E \& WB Provine (eds) The evolutionary synthesis: 413-423. Harvard University Press, Cambridge, Massachusetts, USA.

MCINTOSH RP (1985) The background of ecology: concept and theory. Cambridge University Press, Cambridge, United Kingdom. 300 pp.

NOBLE IR \& R DIRZO (1997) Forests as humandominated ecosystems. Science 277: 522-525.

NOSS RF (1996) The naturalists are dying off. Conservation Biology 10: 1-3.

PAGE LM (2005) Organisms in nature as a central focus for biology. Trends in Ecology \& Evolution 20: 361-362.

PICKETT STA, J KOLASA \& CG JONES (1994) Ecological understanding: the nature of theory and the theory of nature. Academic Press, San Diego, California, USA. 206 pp.

SCHMIDLY DJ (2005) What it means to be a naturalist and the future of natural history at American universities. Journal of Mammalogy 86: 449-456.

VITOUSEK PM, HA MOONEY, J LUBCHENCO \& JM MELILLO (1997) Human domination of Earth's ecosystems. Science 277: 494-499. 